\title{
Comparative Ameliorative Effect of Basil Oil and Moringa oleifera on Lornoxicam- Mediated Histological and Biochemical Alterations in Albino Rat Liver
}

\author{
Hoda I Bahr ${ }^{1}$ and Sameh M Farouk ${ }^{2 *}$ \\ ${ }^{1}$ Biochemistry Department, Faculty of Veterinary Medicine, Suez Canal University, Ismailia 41522, Egypt \\ ${ }^{2}$ Cytology and Histology Department, Faculty of Veterinary Medicine, Suez Canal University, Ismailia 41522, Egypt \\ "Corresponding author: Sameh M. Farouk, Cytology and Histology Department, Faculty of Veterinary Medicine, Suez Canal University, Ismailia 41522, Egypt, Tel: \\ 002-01098395384; Fax: 002-064-3207052; E-mail: dr_smf_hist@yahoo.com or dr_smf_hist@vet.suez.edu.eg
}

Rec date: Sep 18, 2015; Acc date: Jan 21, 2016; Pub date: Jan 23, 2016

Copyright: (c) 2016 Bahr HI, et al. This is an open-access article distributed under the terms of the Creative Commons Attribution License, which permits unrestricted use, distribution, and reproduction in any medium, provided the original author and source are credited.

\begin{abstract}
Background: Although the studies of non-steroidal anti-inflammatory drugs-mediated hepatic dysfunctions has been found to be of great interest to several literatures, a little is known about that of lornoxicam and its possible natural antioxidant herbal therapy.

Objective: The present study aimed to delineate whether intramuscular injection with lornoxicam mediated liver oxidative stress and hepatic degeneration or not, with the same line in an attempt to develop new herbal therapy with basil oil and Moringa oleifera to screen their possible hepatoprotecive impacts.

Methods: 28 adult male albino rats were divided into 4 groups; 7 rats per each. Control, lornoxicam-treated group: rats injected intramuscular with lornoxicam at a dose of $1.4 \mathrm{mg} / \mathrm{kg} / \mathrm{day}$. Lornoxicam $+M$. oleifera -treated group: rats daily exposed to co-administration of lornoxicam and aqueous leaves extract of $M$. oleifera $(500 \mathrm{mg} / 100$

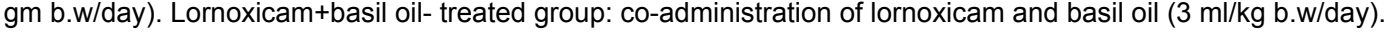

Results: After two weeks of experiment, our findings revealed that Lornoxicam significantly $\mathrm{P}<0.05$ increased serum GPT, GOT and ALP decreased glutathione and antioxidant enzymes, Paraoxonase/arylesterase activity along with elevation in percentage of DNA fragmentation, sialic acid content, butyryl cholinesterase and myeloperoxidase activity. Meanwhile, Basil oil and M. oleifera increased antioxidants activity, decreased DNA fragmentation and down regulate caspase-3 expression. Both herbs showed relative hepatic architectural improvements against lornoxicam induced liver damage.
\end{abstract}

Conclusion: Overall, this article summarizes recent knowledge on lornoxicam- induced hepatic damage and provides new insights into ameliorative role of basil oil and $M$. oleifera leaves.

Keywords: Lornoxicam; Basil oil; Moringa oleifera; Oxidative stress; Inflammatory markers; Apoptosis; Caspase-3

\section{Introduction}

Most of drug therapies such as non-steroidal anti-inflammatory drugs cause great complicated problems for many organs including the liver; resulting in hepatotoxicity [1]. One of these nonsteroidal antiinflammatory drugs is Lornoxicam. Lornoxicam is a new oxicam derivative; it inhibits the migration of polymorphonuclear (PMN) leukocyte, superoxide release from PMN leukocytes and nitric oxide release from macrophages [2].

It was reported in several studies that the most prominent features of many liver diseases resulting from drug/toxicant-induced hepatotoxicity are apoptosis and necrosis [3], prevention of the modes associated with cell death is a main target of therapy. Apoptosis is described as a unique form of programmed cell death that exhibits morphological cellular changes including degradation of nuclear chromatin, cytoplasmic and nuclear condensation, and the fragmentation of the cell into apoptotic bodies [4,5]. The occurrence of apoptosis process is associated with the sequential activation of caspases which cleave death substances required in non-apoptotic cells for many cellular processes such as cell cycle control, DNA repair, cell signaling and structural integrity [6]. Based on liver caspase activity, nuclear import of stress-responsive transcription factors (SRTFs) are important for the initiation of apoptosis process [7]. Caspase-3 is one of caspase family members which depend upon aspartic acid-directed cysteine proteases which then lead to apoptotic cell death by causing loss of both cellular structure and function. The active form of caspase- 3 has the ability to cleave poly (ADP-ribose) polymerase which appears to be involved in DNA repair and cellular integrity [8].

Nowadays, many literatures directed to study the efficacy of plant medicines as natural antioxidants against most of hepatic diseases, meanwhile a little attention concerning basil oil and Moringa oleifera. Basil oil is an essential oil extracted from Ocimum basilicum. In vitro, many scientists established that the basil oil containing compounds have potent antioxidant and antimicrobial properties in addition to its potential for use in treating cancer [9-11]. It is traditionally used for supplementary treatment of stress, asthma and diabetes [12]. However, Moringa is one of the most valuable plants all over the world; it was 
cultivated for medicinal and industrial purposes. It is commonly referred to as the 'tree of life' or 'Drumstick tree' [13]. Moringa is a genus of the plant family Moringaceae [14]. The genus Moringa is made up of about thirteen species, the most common one is called "Moringa oleifera which is found in many tropical and sub-tropical regions. Moeinga oleifera has a great range of medicinal uses with high nutritional values [15]; its seed extract has been shown to protect liver from necrotic injury and fibrosis in rat model [16,17]. The antiinflammatory efficacy of Moreinga oleifera is already recorded [18]. Antioxidant activity of its leaves is very stable at different $\mathrm{pH}$ levels and stable on storage in dark conditions [19].

Recently, there is limited available information regarding the lornoxicam- mediated liver metabolic disorders as well as the hepatoprotective efficacy of Basil oil and Moringa oleifera leaves. Hence, the current study is undertaken to investigate and evaluate the comparative protective effect of both Moringa oleifera and Basil oil as a new herbal therapy against lornoxicam-induced hepatic toxicity in rats.

\section{Materials and Methods}

Drugs: Lornoxicam (lornoxicam $8 \mathrm{mg}$ ) obtained from Global pharmaceutical Co., Cairo, Egypt.

Natural antioxidants: Basil oil (O. basilicum) and Moringa oleifera (M. oleifera) were obtained from local market of Herbs and Medicinal plants, Egypt.

\section{Preparation of aqueous extract of $M$. oleifera leaves}

$1 \mathrm{~g}$ each of the samples was weighted into $10 \mathrm{~mL}$ of distilled water and then left for 24 hours [20]. Filtration of the mixture, the obtained filtrate was centrifuged at $805 \times$ g for 10 minutes. The collected clear supernatant was used for the assay.

Phytochemical screening of Leaves of $M$. oleifera revealed high total antioxidant capacity $(260 \mathrm{mg} / 100 \mathrm{~g})$, rich in flavonols such as total polyphenols (250 mg/100 g), quercetin (100 mg/100 g) kaempferol (34 $\mathrm{mg} / 100 \mathrm{~g})$ and $\beta$-carotene $(34 \mathrm{mg} / 100 \mathrm{~g})$ [21].

\section{Animals preparation}

Adult male albino rats weighting 120-150 gm obtained from Animal House, Faculty of Veterinary Medicine, Suez Canal University, Ismailia, Egypt. They housed in separate well-ventilated cages, under standard conditions, with free access to the standard diet and water ad libitum. All rats used for this experiment were treated in accordance with the guidelines of the National Institutes of Health (NIH) for the Care and Use of Laboratory Animals. The experimental protocols in this study were approved by the institutional research ethics committee at Faculty of Veterinary Medicine, Suez Canal University (Approval No: 201514).

\section{Experimental protocol and treatments}

The animals were divided into 4 groups; each group consisted mainly of 7 rats.

I. Control group rats have free access to water and feed materials. II. LOR- treated group rats were injected intramuscular with lornoxicam at a dose of $1.4 \mathrm{mg} / \mathrm{kg} /$ day [22]. III. LOR $M$. oleifera-treated group rats daily exposed to co-administration of lornoxicam and aqueous leaves extract of $M$. oleifera $(500 \mathrm{mg} / 100 \mathrm{gm}$ b.w/day) by stomach tube for a period of two weeks. IV. LOR+basil oil-treated group rats daily exposed to co-administration of lornoxicam and basil oil ( $3 \mathrm{ml} / \mathrm{kg} \mathrm{b.w} /$ day) by stomach tube also for the aforementioned period of time.

\section{Handling of blood and tissue samples}

Blood samples were individually collected from each rat; serum was separated from non-heparinized blood by centrifugation at $5000 \mathrm{rpm}$ for 10 minutes. Sera were stored at $-20 \mathrm{C}$ for different analysis. After blood collection, animals were sacrificed by cervical decapitation, livers samples were freshly collected then quickly fragmented after removing of any adhering blood or fat tissues, following that fragmented samples were quickly preserved at $-80 \mathrm{C}$. Specimens of liver tissue were homogenized in appropriate buffers for running of biochemical analysis. Other fragments used for histological and immunohistochemical investigations.

\section{Determination of liver function tests}

Assessment of serum liver enzymes, AspAT (GOT), AlaAT (GPT) and Alkaline Phosphatase (ALP) activity carried out according to the method of Belfield [23] and Evelson [24] respectively following the manufacturer's instructions (Biodiagnostic, Egypt).

\section{Evaluation of oxidative stress indices}

Liver samples were homogenized in 10 volumes $(1: 10, \mathrm{w} / \mathrm{v})$ of 20 $\mathrm{mM}$ sodium phosphate buffer, $\mathrm{pH} 7.4$ containing $140 \mathrm{mM} \mathrm{KCl}$. Homogenates were centrifuged at $750 \times \mathrm{g}$ for $10 \mathrm{~min}$ at $4^{\circ} \mathrm{C}$ to discard nuclei and cell debris [25]. The pellet was discarded and the supernatant was separated and used for measuring oxidative stress and antioxidant markers. Estimation of reduced glutathione (GSH) level, Catalase (CAT), Glutathione peroxidase (GPx), Glutathione reductase (GR) and Glucose-6-phosphate dehydrogenase (G6PD) activity were performed by the method of Aebi [26], Paglia [27], Goldberg [28], Kornberg [29] and Montgomery [30] respectively. Nitric oxide (NO) level was measured by the method of Satoh [31]. Lipid peroxidation was ascertained by the formation of Malondialhyde (MDA) or thiobarbituric acid-reactive substances (TBA-RS) level which was estimated by the modified thiobarbituric acid method of [32] and Perandones [33] following the manufacturer's instructions (Biodiagnostic, Egypt). The diphenylamine (DPA) reaction applied for detection of DNA fragmentation which performed by the method of Denny [34].

\section{Assessment of inflammatory markers}

Estimation of sialic acid (N.acetylneuraminic acid) content of glycoprotein was carried by the methods of Warren, [35-37]. The molecular extinction coefficient of N. acetylneuraminic acid is 57,000. Butyrylcholinesterase (BChE) activity was measured according to Sáez-Valero and Aviram [38,39] following the manufacturer's instructions (Biodiagnostic, co., Giza Egypt). Arylesterase (ARE) activity of paraoxonase was measured spectrophotometrically as described by Kettle [40]; the activity was calculated assuming molar extinction coefficient is $1310 \mathrm{M}^{-1} \mathrm{~cm}^{-1}$. The results are expressed in $\mathrm{U} / \mathrm{mg}$ protein, $1 \mathrm{U}$ hydrolyzes $1 \mu \mathrm{mol}$ of phenyl acetate $/ \mathrm{min}$. Myeloperoxidase (MPO) is the most abundant protein in neutrophils (also found in monocytes) is well- known indicator of neutrophil infiltration. Hypochlorous acid production by myeloperoxidase was determined by measuring accumulation of taurine chloramine [41]. Protein levels were measured by the method of [42] following the 
manufacturer's instructions (Biodiagnostic, Egypt) using bovine serum albumin as standard.

\section{Histological and histochemical investigations}

To study the conventional histological and histochemical findings for liver, samples from each rat in all experimental groups were rapidly collected in $10 \%$ neutral buffer formalin for at least one week. The formalin fixed specimens were subjected to the following processes; dehydration by gradual series of ethyl alcohol, clearance by immersing in xylene and finally embedding in hard paraffin. The paraffin embedded livers were cut into $5 \mu \mathrm{m}$ sections with a microtome. The prepared paraffin sections were stained by Heamatoxylin and Eosin for general histomorphological changes and Masson's trichrome for demonstration of collagenic fibers according to [43]. The sections were examined microscopically and the photomicrographs were taken using Olympus BX41 research optical photomicroscope fitted with an Olympus DP25 digital camera, Cytology and Histology department, Faculty of Veterinary Medicine, Suez Canal University.

\section{Immunohistochemical staining}

Caspase-3 immunoreactivity was detected according to [44]. Liver samples were immersed in $4 \%$ paraformaldehyde. The specimens were subjected to the routine histological procedures and then embedded in hard paraffin. The obtained $5 \mu \mathrm{m}$ paraffin sections were deparaffinized in xylene then rehydrated through descending series of ethanol. Blocking of endogenous peroxidase activity was achieved by incubation of sections into. $3 \% \mathrm{H}_{2} \mathrm{O}_{2}$ in methanol for $10 \mathrm{~min}$. Sections were heated at $120^{\circ} \mathrm{C}$ with citrate buffer $\mathrm{pH}$ 6. The section washed with PBST then subjected to blocking buffer (10\% bovine serum albumin) for 2 hours at room temperature to prevent nonspecific binding of the primary antibody. Sections were incubated overnight at $4^{\circ} \mathrm{C}$ with antiCaspase-3 antibody (Abcam, ab4051) (1:50 dilution). After incubation, sections were washed in PBST then incubated with biotinylated goatanti-rabbit-IgG secondary antibody (1:200 dilutions, Santa Cruz Biotechnology, USA) for one hour at room temperature. The reaction was visualized using DAB-nickel revelation. Cellular nuclei were counterstained with Harry's haematoxylin. Stained sections were dehydrated, cleared, mounted and cover slipped.

The percentage of hepatocytic Caspase-3 expression in all experimental groups were detected according to [45] by counting the apoptotic hepatocytes in six random selected high-power fields (objective lens $\times 40$ ) per slide in each experimental group, the apoptotic cells percentage further assessed according to the following formula: apoptosis index $=($ the number of apoptotic hepatocytes/total number of nucleated hepatocytes $) \times 100 \%$.

\section{Statistical analysis}

Statistical analysis was performed using standard one-way analysis of variance (ANOVA) according to Bianchi [46] followed by the Duncan Test to assess significant differences among treatment groups. Descriptive statistics and tests of significance were demonstrated by SPSS version 22 for Windows and expressed as mean \pm SE. The criterion for statistical significance was set at $\mathrm{P}<0.05$.

\section{Results}

Effect of Basil oil (3 ml/kg b.w/day) and M. oleifera (500 $\mathrm{mg} / 100 \mathrm{gm} \mathrm{b.w/day)} \mathrm{on} \mathrm{liver} \mathrm{function} \mathrm{tests} \mathrm{in} \mathrm{lornoxicam}$ $(1.4 \mathrm{mg} / \mathrm{kg} / \mathrm{day})$ treated rats

Lornoxicam significantly $\mathrm{P}<0.05$ increased serum GPT, GOT and ALP comparing to normal control group. In contrary, basil oil and $M$. oleifera reduced GPT, ALP activity comparing to lornoxicam-treated group. $M$. oleifera return GOT to normal values (Figure 1A, 1B and 1C).

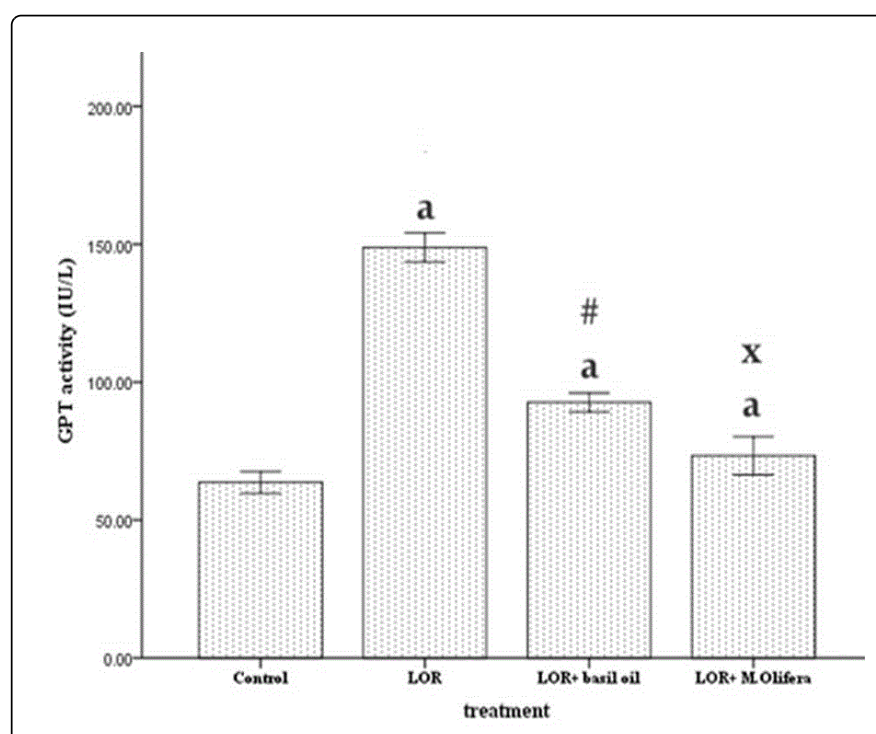

Figure 1A: Effect of Basil oil ( $3 \mathrm{ml} / \mathrm{kg}$ b.w/day) and M. oleifera (500 $\mathrm{mg} / 100$ gmb.w/day) on liver function tests in lornoxicam (1.4 $\mathrm{mg} / \mathrm{kg} /$ day) treated rats. (A) GPT (AlaAT). Values are expressed as mean \pm S.E.M. and analyzed using one-way ANOVA followed by the Duncan analysis at $\mathrm{P}<0.05$. aP compared to control, \# $\mathrm{P}$ compared to lornoxicam and lornoxicam $+M$. oleifera -treated groups, xP compared tolornoxicam and lornoxicam+basil oiltreated groups.

\section{Effect of Basil oil (3 ml/kg b.w/day) and M. oleifera (500 $\mathrm{mg} / 100 \mathrm{gm}$ b.w/day) on oxidative stress indices in lornoxicam $(1.4 \mathrm{mg} / \mathrm{kg} /$ day) treated rats}

Lornoxicam significantly $\mathrm{P}<0.05$ decreased glutathione and antioxidant enzymes along with elevation in percentage of DNA fragmentation among different groups. Basil oil and $M$. oleifera increased reduced glutathione level and decreased DNA fragmentation comparing to lornoxicam- treated group. M. oleifera returns catalase, glutathione peroxidase, glutathione reductase and glucose-6phosphate dehydrogenase activity to normal values. Basil oil and $M$. oleifera able to restore MDA and nitric oxide level toward normal values (Figure 2A, 2B, 2C, 2D, 2E, 2F, 2G and 2H). 
Citation: Bahr HI, Farouk SM (2016) Comparative Ameliorative Effect of Basil Oil and Moringa oleifera on Lornoxicam- Mediated Histological and

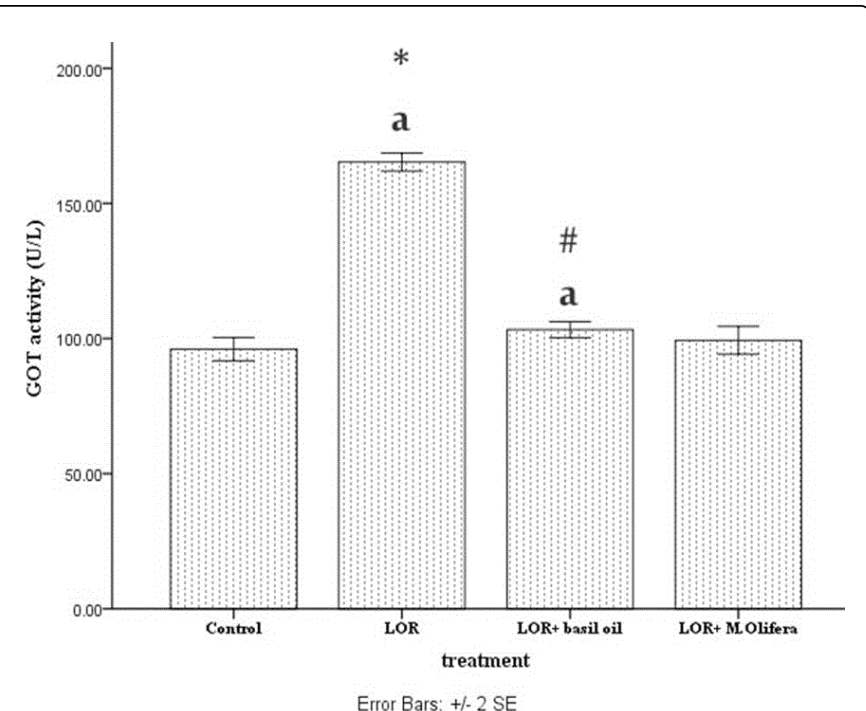

Figure 1B: Effect of Basil oil ( $3 \mathrm{ml} / \mathrm{kg}$ b.w/day) and M. oleifera (500 $\mathrm{mg} / 100$ gmb.w/day) on liver function tests in lornoxicam $(1.4$ $\mathrm{mg} / \mathrm{kg} /$ day) treated rats. GOT (AspAT). Values are expressed as mean \pm S.E.M. and analyzed using one-way ANOVA followed by the Duncan analysis at $\mathrm{P}<0.05$. aP compared to control, \# $\mathrm{P}$ compared to lornoxicam and lornoxicam $+M$. oleifera -treated groups, xP compared tolornoxicam and lornoxicam+basil oiltreated groups.

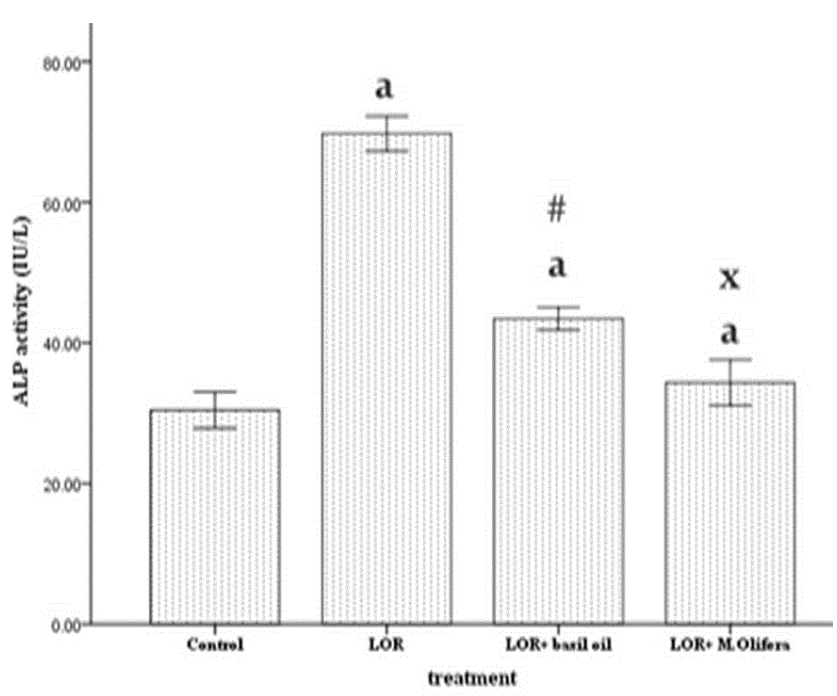

Figure 1C: Effect of Basil oil ( $3 \mathrm{ml} / \mathrm{kg}$ b.w/day) and M. oleifera (500 $\mathrm{mg} / 100$ gmb.w/day) on liver function tests in lornoxicam (1.4 $\mathrm{mg} / \mathrm{kg} /$ day) treated rats. Alkaline phosphatse (ALP). Values are expressed as mean \pm S.E.M. and analyzed using one-way ANOVA followed by the Duncan analysis at $\mathrm{P}<0.05$. aP compared to control, \# $\mathrm{P}$ compared to lornoxicam and lornoxicam $+M$. oleifera -treated groups, $\mathrm{xP}$ compared tolornoxicam and lornoxicam+basil oiltreated groups.

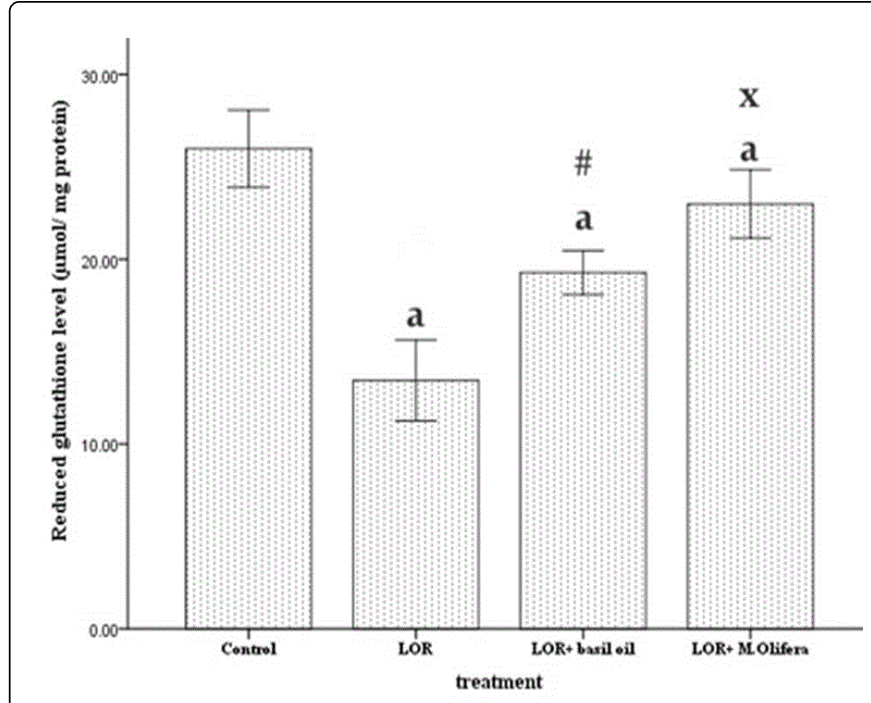

Figure 2A: Effect of Basil oil ( $3 \mathrm{ml} / \mathrm{kg}$ b.w/day) and M. oleifera (500 $\mathrm{mg} / 100$ gmb.w/day) on oxidative stress indices in lornoxicam (1.4 $\mathrm{mg} / \mathrm{kg} /$ day) treated rats. Reduced glutathione, GSH. Values are expressed as mean \pm S.E.M. and analyzed using one-way ANOVA followed by the Duncan analysis at $\mathrm{P}<0.05$. aP compared to control, \# $\mathrm{P}$ compared to lornoxicam and lornoxicam $+M$. oleifera -treated groups, $\mathrm{xP}$ compared to lornoxicam and lornoxicam+basil oiltreated groups.

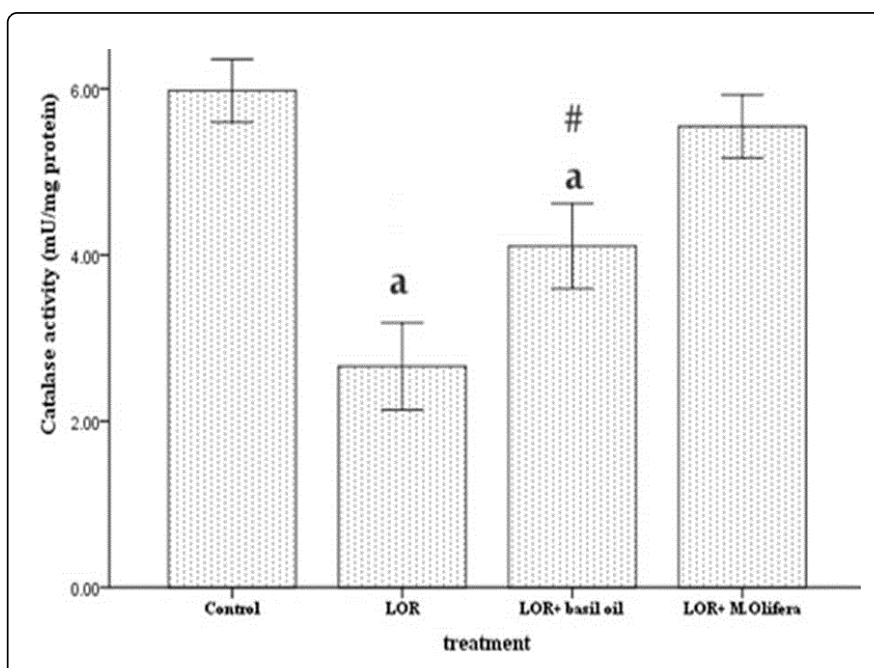

Figure 2B: Effect of Basil oil ( $3 \mathrm{ml} / \mathrm{kg}$ b.w/day) and M. oleifera (500 $\mathrm{mg} / 100 \mathrm{gmb} . \mathrm{w} /$ day) on oxidative stress indices in lornoxicam (1.4 $\mathrm{mg} / \mathrm{kg} /$ day) treated rats. Catalase (CAT) activity. Values are expressed as mean \pm S.E.M. and analyzed using one-way ANOVA followed by the Duncan analysis at $\mathrm{P}<0.05$. aP compared to control, \# $\mathrm{P}$ compared to lornoxicam and lornoxicam $+M$. oleifera -treated groups, xP compared to lornoxicam and lornoxicam+basil oiltreated groups. 
Citation: Bahr HI, Farouk SM (2016) Comparative Ameliorative Effect of Basil Oil and Moringa oleifera on Lornoxicam- Mediated Histological and

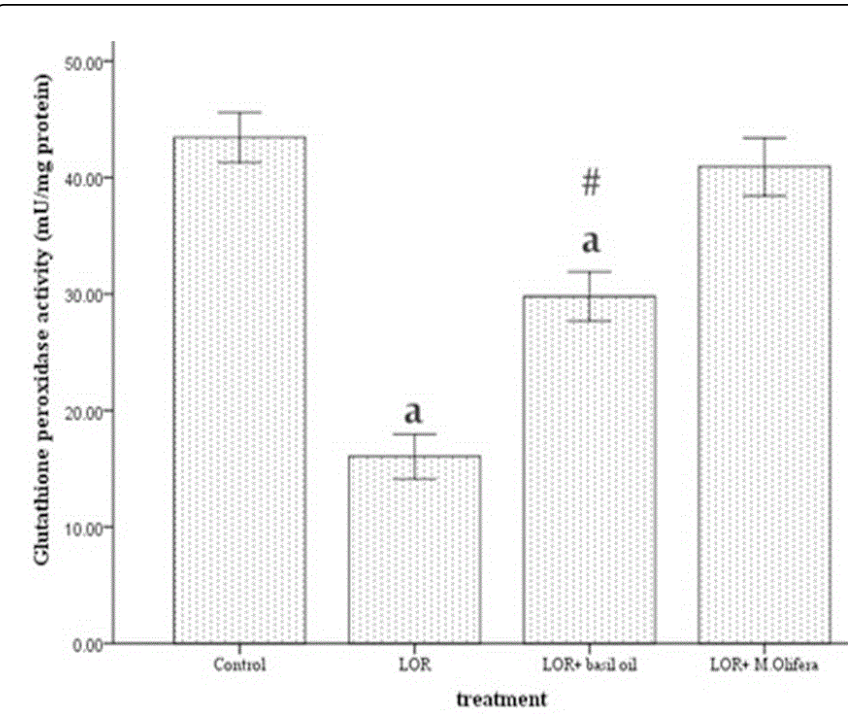

Figure 2C: Effect of Basil oil ( $3 \mathrm{ml} / \mathrm{kg}$ b.w/day) and M. oleifera (500 $\mathrm{mg} / 100 \mathrm{gmb} . \mathrm{w} /$ day $)$ on oxidative stress indices in lornoxicam $(1.4$ $\mathrm{mg} / \mathrm{kg} /$ day) treated rats. Glutathione peroxidase (GPx) activity. Values are expressed as mean \pm S.E.M. and analyzed using one-way ANOVA followed by the Duncan analysis at $\mathrm{P}<0.05$. aP compared to control, \# P compared to lornoxicam and lornoxicam + M. oleifera -treated groups, xP compared to lornoxicam and lornoxicam+basil oil- treated groups.

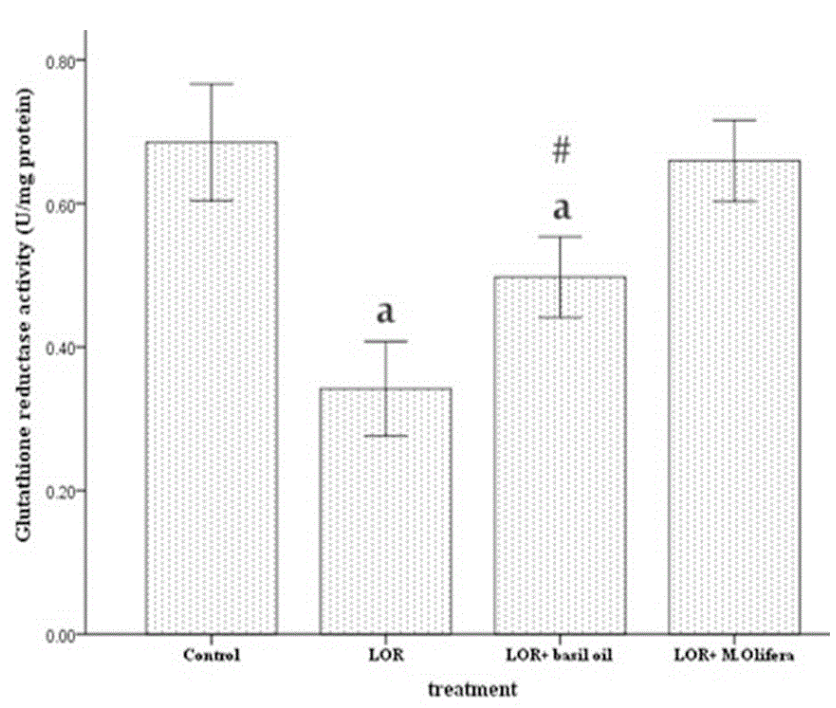

Figure 2D: Effect of Basil oil ( $3 \mathrm{ml} / \mathrm{kg}$ b.w/day) and M. oleifera (500 $\mathrm{mg} / 100 \mathrm{gmb} . \mathrm{w} /$ day) on oxidative stress indices in lornoxicam (1.4 $\mathrm{mg} / \mathrm{kg} /$ day) treated rats. . Values are expressed as mean \pm S.E.M. and analyzed using one-way ANOVA followed by the Duncan analysis at $\mathrm{P}<0.05$. aP compared to control, \# $\mathrm{P}$ compared to lornoxicam and lornoxicam $+M$. oleifera -treated groups, $\mathrm{xP}$ compared to lornoxicam and lornoxicam+basil oil- treated groups.

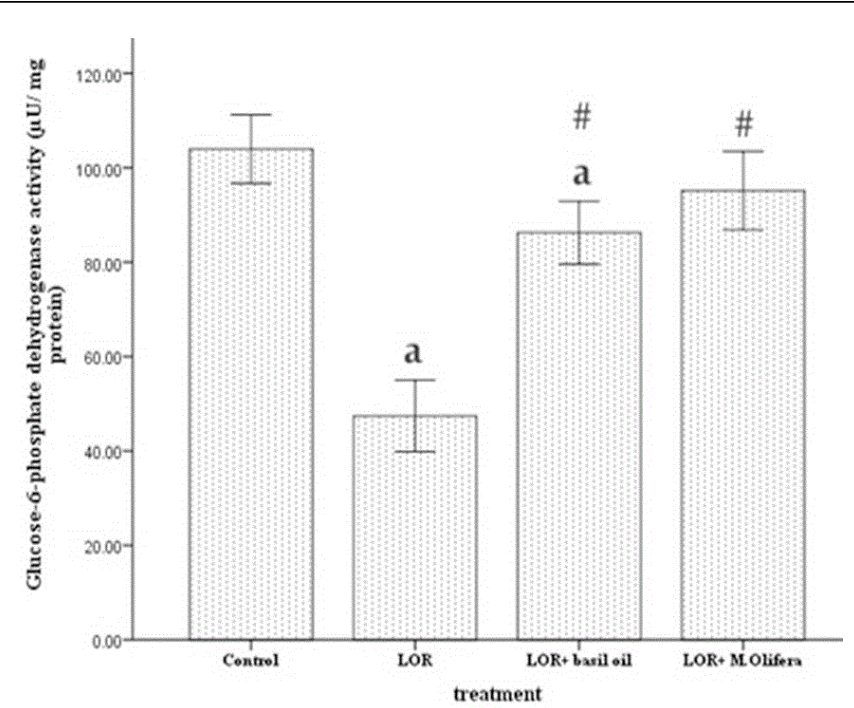

Figure 2E: Effect of Basil oil ( $3 \mathrm{ml} / \mathrm{kg}$ b.w/day) and M. oleifera (500 $\mathrm{mg} / 100 \mathrm{gmb} . \mathrm{w} /$ day) on oxidative stress indices in lornoxicam (1.4 $\mathrm{mg} / \mathrm{kg} /$ day) treated rats. Glucose-6-phosphate dehydrogenase (G6PD) activity. Values are expressed as mean \pm S.E.M. and analyzed using one-way ANOVA followed by the Duncan analysis at $\mathrm{P}<0.05$. aP compared to control, \# $\mathrm{P}$ compared to lornoxicam and lornoxicam $+M$. oleifera -treated groups, $\mathrm{xP}$ compared to lornoxicam and lornoxicam+basil oil- treated groups.

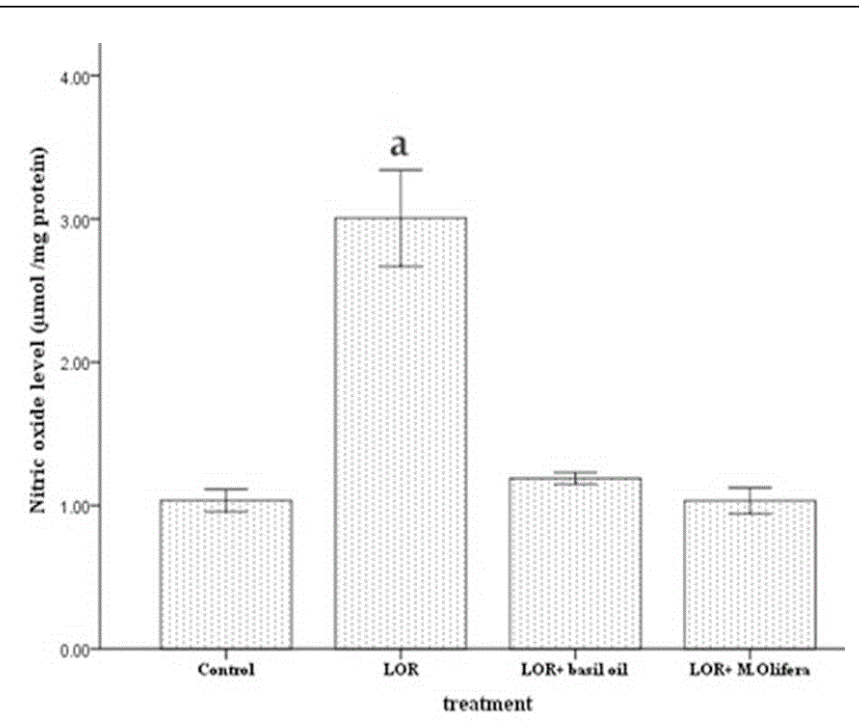

Figure 2F: Effect of Basil oil ( $3 \mathrm{ml} / \mathrm{kg}$ b.w/day) and M. oleifera (500 $\mathrm{mg} / 100 \mathrm{gmb} . \mathrm{w} /$ day) on oxidative stress indices in lornoxicam (1.4 $\mathrm{mg} / \mathrm{kg} /$ day) treated rats. Nitric oxide (NO) level. Values are expressed as mean \pm S.E.M. and analyzed using one-way ANOVA followed by the Duncan analysis at $\mathrm{P}<0.05$. aP compared to control, \# $\mathrm{P}$ compared to lornoxicam and lornoxicam $+M$. oleifera -treated groups, $\mathrm{xP}$ compared to lornoxicam and lornoxicam+basil oiltreated groups. 


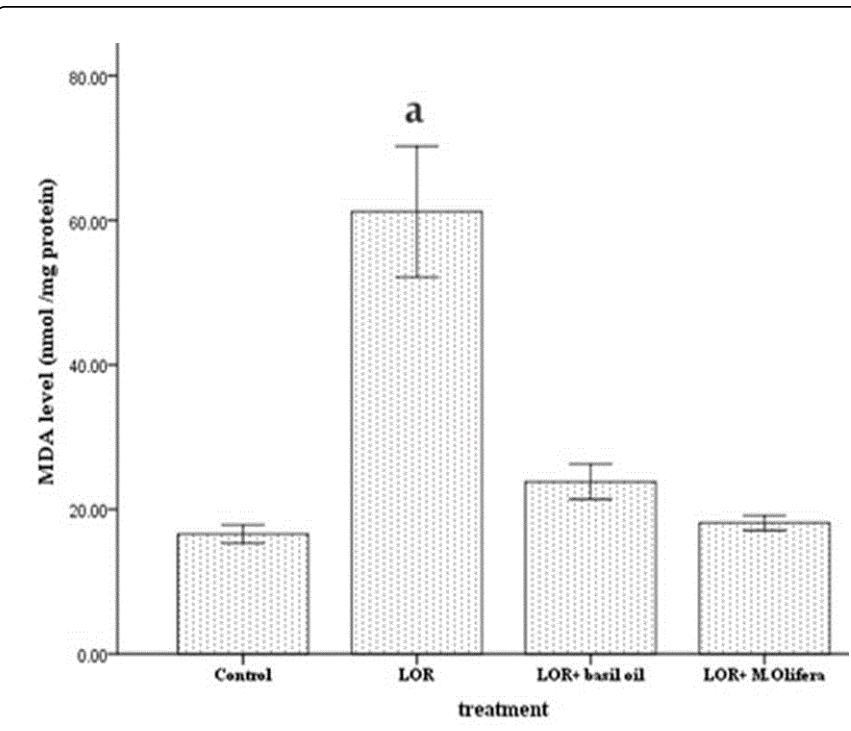

Figure 2G: Effect of Basil oil ( $3 \mathrm{ml} / \mathrm{kg}$ b.w/day) and M. oleifera (500 $\mathrm{mg} / 100 \mathrm{gmb} . \mathrm{w} /$ day) on oxidative stress indices in lornoxicam (1.4 $\mathrm{mg} / \mathrm{kg} /$ day) treated rats. Malondialhyde (MDA) level. Values are expressed as mean \pm S.E.M. and analyzed using one-way ANOVA followed by the Duncan analysis at $\mathrm{P}<0.05$. aP compared to control, \# P compared to lornoxicam and lornoxicam $+M$. oleifera -treated groups, $\mathrm{xP}$ compared to lornoxicam and lornoxicam+basil oiltreated groups.

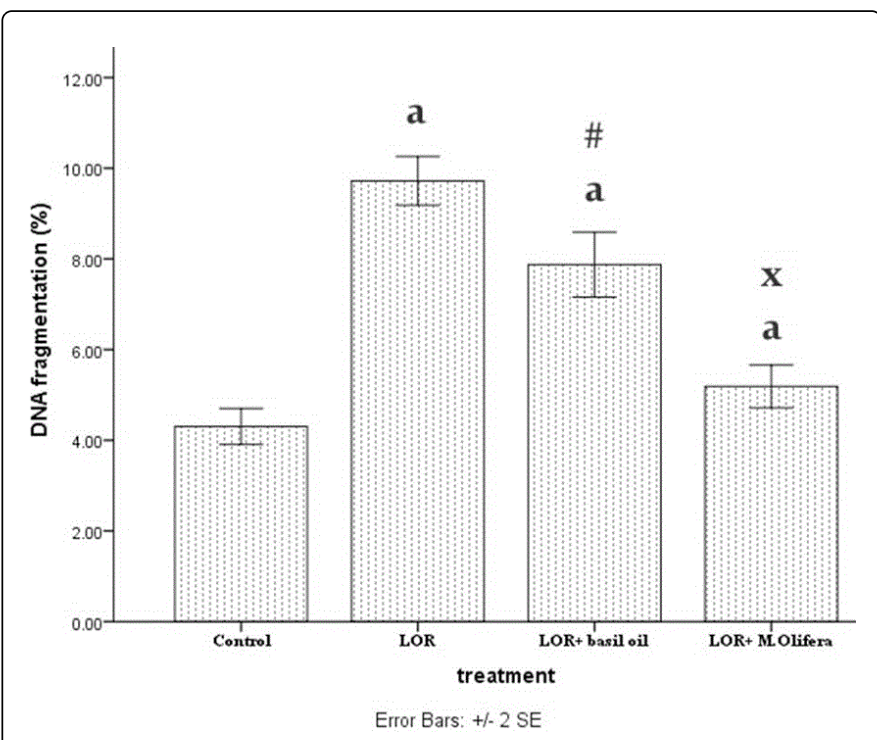

Figure 2H: Effect of Basil oil ( $3 \mathrm{ml} / \mathrm{kg}$ b.w/day) and M. oleifera (500 $\mathrm{mg} / 100 \mathrm{gmb} . \mathrm{w} /$ day) on oxidative stress indices in lornoxicam (1.4 $\mathrm{mg} / \mathrm{kg} /$ day) treated rats. DNA fragmentation (\%). Values are expressed as mean \pm S.E.M. and analyzed using one-way ANOVA followed by the Duncan analysis at $\mathrm{P}<0.05$. aP compared to control, \# $\mathrm{P}$ compared to lornoxicam and lornoxicam $+M$. oleifera -treated groups, xP compared to lornoxicam and lornoxicam+basil oiltreated groups.

\section{Effect of Basil oil ( $3 \mathrm{ml} / \mathrm{kg} \mathrm{b.w/day)} \mathrm{and} \mathrm{M.} \mathrm{oleifera} \mathrm{(500}$ $\mathrm{mg} / 100 \mathrm{gm}$ b.w/day) on inflammatory markers in lornoxicam $(1.4 \mathrm{mg} / \mathrm{kg} /$ day $)$ treated rats}

Current data showed decreased Paraoxonase/arylesterase activity along with elevation in sialic acid content, butyryl cholinesterase and myeloperoxidase activity in lornoxicam- treated group than normal values. However, basil oil increased Paraoxonase/arylesterase activity comparing to lornoxicam-treated group. $M$. oleifera returns butyryl cholinesterase, Paraoxonase/arylesterase activity and sialic acid level to normal values. Basil oil and $M$. oleifera have the ability to restore myeloperoxidase activity toward its normal values (Figure 3A, 3B, 3C and 3D).

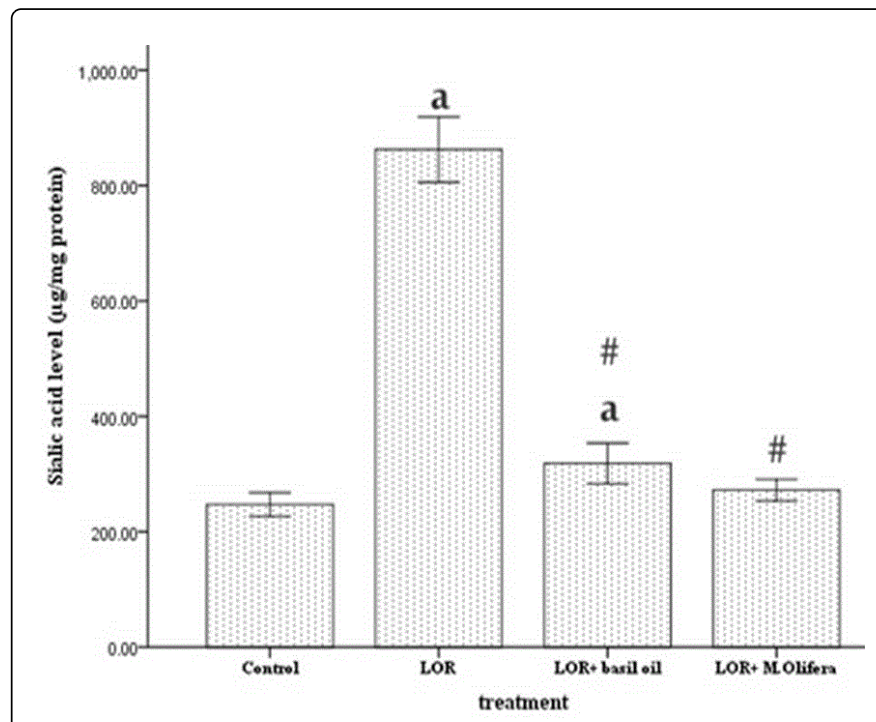

Figure 3A: Effect of Basil oil (3 ml/kg b.w/day) and M. Oleifera (500 $\mathrm{mg} / 100 \mathrm{gmb} . \mathrm{w} /$ day) on inflammatory markers in lornoxicam (1.4 $\mathrm{mg} / \mathrm{kg} /$ day) treated rats. Sialic acid (N.acetylneuraminic acid) content of glycoprotein. Values are expressed as mean \pm S.E.M. and analyzed using one-way ANOVA followed by the Duncan analysis at $\mathrm{P}<0.05$. aP compared to control,\# $\mathrm{P}$ compared tolornoxicam and lornoxicam $+M$. oleifera - treated groups, $\mathrm{xP}$ compared tolornoxicam and lornoxicam+basil oil- treated groups.

\section{Histological and histochemical evaluation}

Liver sections of control rats revealed normal lobular architecture with centrally located veins and normal polyhedral hepatic cells forming radiating hepatic cords enclosing hepatic sinusoids and Kupffer cells (Figure 4A). Meanwhile Lornoxicam-treated group showed diffuse vacuolar cytoplasmic degeneration of hepatocyte and severe congestion of portal blood vessels and central veins as well as hepatic sinusoids after two weeks of drug administration (Figure $4 \mathrm{~B}$ and $4 \mathrm{C})$. 


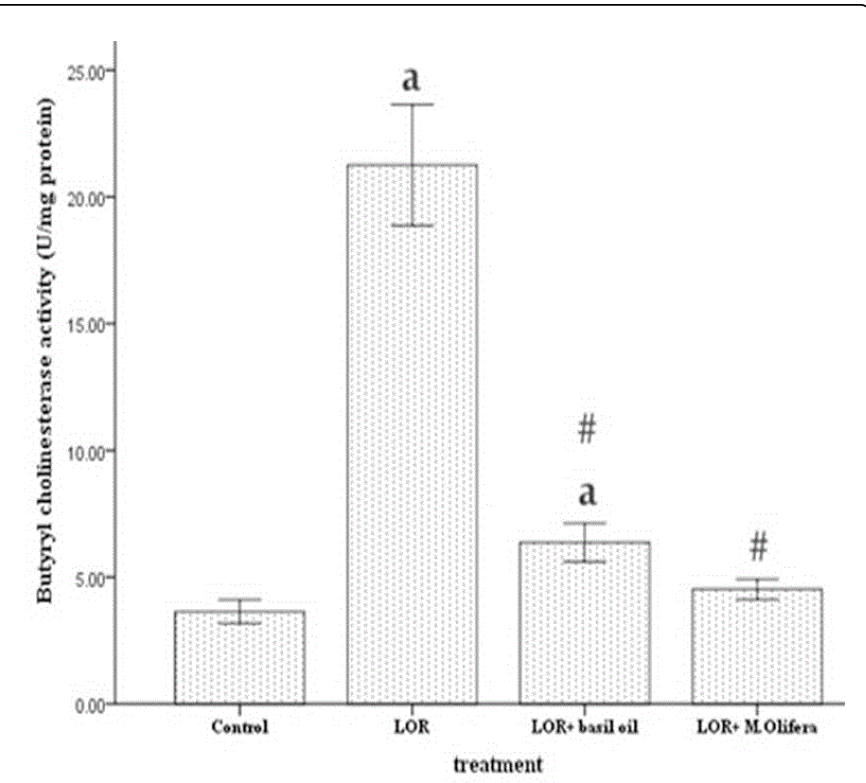

Figure 3B: Effect of Basil oil ( $3 \mathrm{ml} / \mathrm{kg}$ b.w/day) and M. oleifera (500 $\mathrm{mg} / 100 \mathrm{gmb} . \mathrm{w} /$ day) on inflammatory markers in lornoxicam (1.4 $\mathrm{mg} / \mathrm{kg} /$ day) treated rats. Butyrylcholinesterase (BChE) activity. Values are expressed as mean \pm S.E.M. and analyzed using one-way ANOVA followed by the Duncan analysis at $\mathrm{P}<0.05$. aP compared to control,\# $\mathrm{P}$ compared tolornoxicam and lornoxicam $+M$. oleifera - treated groups, $\mathrm{xP}$ compared tolornoxicam and lornoxicam+basil oil- treated groups.

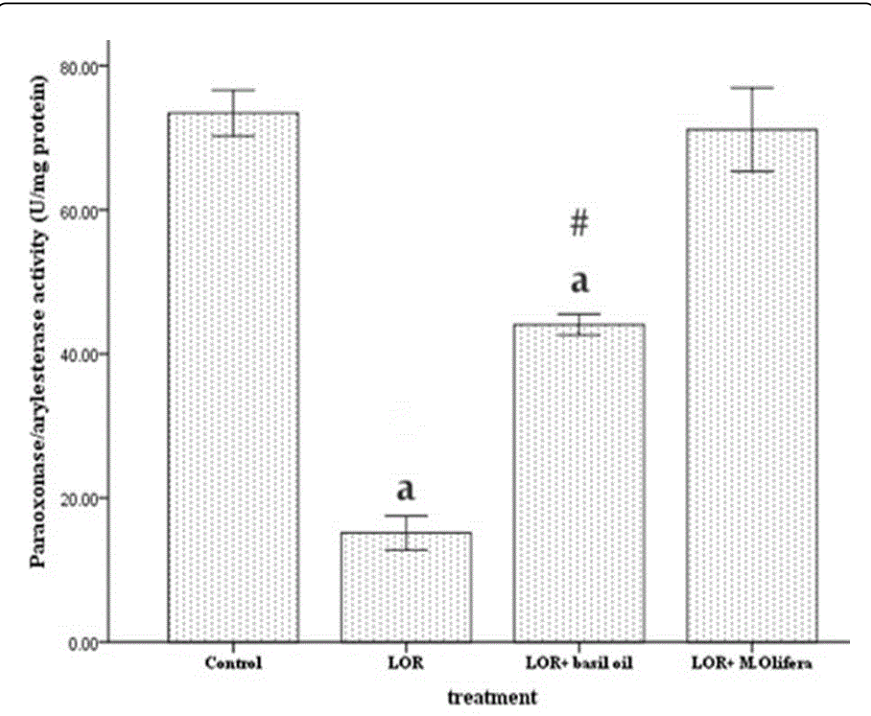

Figure 3C: Effect of Basil oil (3 ml/kg b.w/day) and M. oleifera (500 $\mathrm{mg} / 100 \mathrm{gmb} . \mathrm{w} /$ day) on inflammatory markers in lornoxicam (1.4 $\mathrm{mg} / \mathrm{kg} /$ day) treated rats. Paraoxonase/arylesterase activity. Values are expressed as mean \pm S.E.M. and analyzed using one-way ANOVA followed by the Duncan analysis at $\mathrm{P}<0.05$. aP compared to control,\# $\mathrm{P}$ compared tolornoxicam and lornoxicam $+M$. oleifera - treated groups, xP compared tolornoxicam and lornoxicam+basil oil- treated groups.

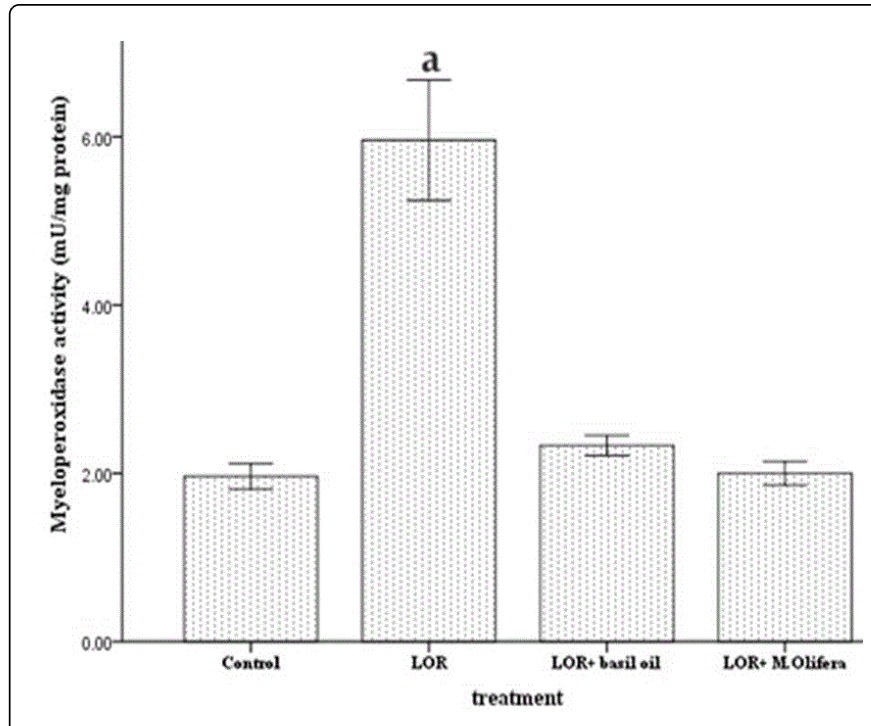

Figure 3D: Effect of Basil oil ( $3 \mathrm{ml} / \mathrm{kg}$ b.w/day) and M. oleifera (500 $\mathrm{mg} / 100 \mathrm{gmb} . \mathrm{w} /$ day) on inflammatory markers in lornoxicam (1.4 $\mathrm{mg} / \mathrm{kg} / \mathrm{day}$ ) treated rats. Myeloperoxidase (MPO) activity. Values are expressed as mean \pm S.E.M. and analyzed using one-way ANOVA followed by the Duncan analysis at $\mathrm{P}<0.05$. aP compared to control,\# $\mathrm{P}$ compared tolornoxicam and lornoxicam $+M$. oleifera - treated groups, $\mathrm{xP}$ compared tolornoxicam and lornoxicam+basil oil- treated groups.

Focal discrete hepatocellular necrosis recorded with pyknosis, karryorrhexis and karryolysis of their nuclei. A mild proleiferation and hyperplasia of bile duct also observed, in addition to mild lymphocytic infiltration as well as mild early fibrosis (Figure 4B and 4C). LOR+basil oil- treated group as well as LOR+Moringa oleifera treated group showed relative improvement among hepatocytes against Lornoxicaminduced liver damage including normal integrity of hepatic lobules with a few cellular changes. LOR+basil oil-treated group showed vacuolar degeneration in few hepatic cells and mild congestion of blood sinusoids (Figure 4D). The hepatocytes of LOR+Moringa oleifera-treated group showed focal areas of mild vacuolar degeneration with absence of necrosis and fibrous tissue proleiferation (Figure 4E).

Concerning the sections stained by Masson trichrome, absence of collagenic fibrous connective tissues in control and LOR+Moringa oleifera - treated groups (Figure 5A and 4E). Meanwhile mild early fibrosis around the hepatic areas was noticed in Lornoxicam-treated groups (Figure 5B and 5C). Few delicate amount of fibrous tissues were noticed among the portal areas of $\mathrm{LOR}+$ basil oil- treated group (Figure 5D).

\section{Caspase- 3 expression}

Immunohistochemical studies of Caspase-3 revealed that all experimental groups' livers showed detectable caspase-3 activity (Figure 6A, 6B, 6C, 6D and 6E). Lornoxicam-treated group showed increasing of the positively intracytoplasmic brown expression of Caspase-3. LOR+ basil oil- treated and LOR+Moringa oleifera-treated groups significantly $\mathrm{P}<0.05$ reduced caspase-positive apoptotic cells comparing to lornoxicam- treated group. 


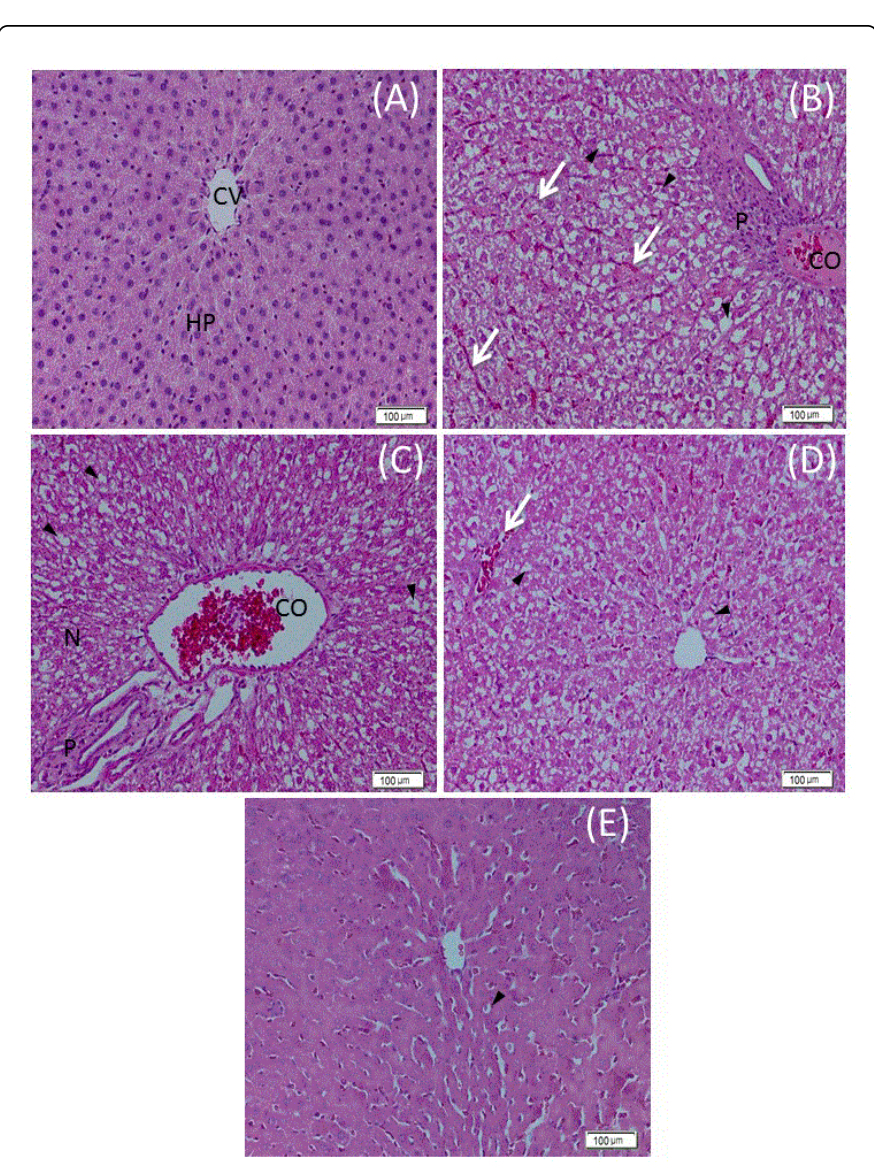

Figure 4: Photomicrographs of liver sections of different treatment groups stained by $\mathrm{H} \& \mathrm{E}$. (A) Control group showing normal histological structure of the hepatic parenchyma (HP) without any fibrosis or cirrhosis around central vein (CV). (B and C) Lornoxicam-treated group showing dilatation and congestion of blood sinusoids (arrows), central veins and portal blood vessels (CO), diffuse vacuolar degeneration (head arrows), focal hepatic necrosis $(\mathrm{N})$ along with lymphocytic infiltration and proleiferation of bile duct (P). (D) LOR+ Basil oil-treated group showing mild hepatocytic vacuolar degeneration (head arrows) and few congested blood sinusoids (arrow). (E) LOR+ M. oleifera -treated group showing mild vacuolar degeneration (head arrows) with absence of fibrous tissue proleiferation.

Data of the present study of apoptotic indices showed highly significant differences among the four experimental groups. The highest apoptotic index was observed in LOR- treated group followed by LOR+ basil oil- treated group then LOR+Moringa oleifera - treated group, with the lowest estimate in control group $(\mathrm{n}=6, \mathrm{P}<0.05)$ (Figure $6 \mathrm{~F})$.

\section{Discussion}

The main objective of the present study was to evaluate the protective effects of basil oil and $M$. oleifera leaves extract on lornoxicam-induced hepatotoxicity, in line with the consideration that oxygen-free radicals are important mediators for hepatic failure. In the current work, we choose the lornoxicam dose of $1.3 \mathrm{mg} / \mathrm{kg}$ that was successful in curbing hyperalgesia in rats in study of Bonnabry [47], but our study applied I.M injection instead of I.P.

In the present study, LOR administration caused marked hepatic dysfunction as evidenced by the significant increase in serum GPT, GOT, ALP. As well as decrement in hepatic GSH and antioxidant enzymes along with elevated lipid peroxidation were recorded. These may attributed to that, cytochrome P-450 isozymes (CYP2C9, CYP2D6 and CYP3A4) found to catalyze the biotransformation of lornoxicam to one of its major metabolites, 5 '-hydroxy-lornoxicam in liver accompanying by free radical production [48,49]. Hence, LOR might consume GSH for removal of oxygen radicals. Also, polyunsaturated lipids are sensitive to these attacks yields MDA. Consequently, and taking into account that oxidative stress is the potential way involved in LOR-induced hepatic dysfunction.

Our data highlighted that lornoxicam create inflammatory process in liver that evoked by decreased Paraoxonase/arylesterase activity along with elevation in sialic acid content, butyryl cholinesterase and myeloperoxidase activity. Tissue MPO is an oxidative enzyme and indicator for neutrophil activity that generates hypochlorous acid damaging nearby tissues [50]. Paraoxonase 1 (PON1) is antioxidant enzyme and has three enzymatic molecules, PON, arylesterase (ARE), and dyazoxonase [51,52]. Butyrylcholinesterase (BChE) and paraoxonase 1 (PON1) are synthesized in liver and related with inflammation, meanwhile $\mathrm{BChE}$ is protected from oxidative stress by PON1 [53]. Increased activity of BChE leads to decreased acetylcholine level reducing its anti-inflammatory actions; consequently enhance local and systemic inflammation [54]. Significant differences in the stimulatory effect of LOR on BuChE and MPO activity and inhibitory effect on antioxidant system obtained in this experiment hypothesize increased levels of hepatic oxidative stress and inflammatory biomarkers.

In the current work, there is a significant increase in liver NO in LOR-treated rats. This supported by the finding of Kandeel and Choi $[55,56]$ whom noted that nitric oxide produced by iNOS is accompanied by elevated oxidative stress and mitochondrial damage inducing hepatic cellular damage. It is demonstrated that prolonged NO release stimulate apoptosis [57] by activating caspase family proteases that cleaves the inhibitor of caspase-activated DNase (ICAD) resulting in DNA fragmentation as reported in the current experiment. These findings supported by histological and immunohistochemical finding where fibrotic, necrotic and apoptotic hepatocytes observed which further adversely affect the liver functions. It is reported that liver tissue damages occur due to necrosis, apoptosis, and that of their histological architectures changes are observable in oxidative stressinduced impaired hepatic functions [58]. As well as, there is a marked increase in the hepatocytic expression of Caspase-3 immunostaining of Lornoxicam-treated group. Such findings were enough to infer that lornoxicam negatively affect liver function.

In recent years, natural antioxidants being safe and non-toxic are gaining much attention and therefore, the research is directed towards identification of plant foods with antioxidant ability that may be used for human Consumption [59]. Ocimum basilicum L. (Lamiaceae, $O$. basilicum, sweet basil) is an Egyptian plant used as a folkloric remedy in Egyptian traditional medicine. Much research into the health benefits conferred by the essential oils found in $O$. basilicum that have potent antioxidant oil as linalool, isoanethole and eugenol as major components has shown appreciable antioxidant activities, comparable to that of a-tocopherol [60]. Basil oil can overcome LOR- induced hepatic damage by attenuating oxidative stress. Remarkably inhibited 
Citation: Bahr HI, Farouk SM (2016) Comparative Ameliorative Effect of Basil Oil and Moringa oleifera on Lornoxicam- Mediated Histological and Biochemical Alterations in Albino Rat Liver. J Veterinar Sci Technol 7: 309. doi:10.4172/2157-7579.1000309

Page 9 of 11

BChE acitivty during co-administration of LOR with basil oil supported by the hypothesis [61]. These ameliorations may be attributed to the essential oils of basil that have radical-scavenging and antioxidant properties.

Aqueous extract of $M$. oleifera leaves has an impressive range of medicinal uses with high nutritional value related to its antioxidant compounds like Vitamins $\mathrm{C}, \mathrm{E}$ and $\beta$-carotene in concentrated form. $M$. oleifera-treated rats evoked increased reduced glutathione level and decreased DNA fragmentation with normalization of other altered biomarkers. Our suggestion directed toward that aqueous extract of dried $M$. oleifera leaves containing 2,2-diphenyl-1-picrylhydrazyl, superoxide, hydroxyl radical scavenging activity favoring inhibition of lipid peroxidation. As well as, phenol and flavonoids content [62]. $M$. oleifera is beneficial to protect liver from necrotic injury and fibrosis in rat model [18]. Both in vivo and in vitro experimental models show that DNA can be protected from oxidative damage by $M$. oleifera $[63,64]$. All these previous observations confirm that recorded in the present work; liver sections of $M$. oleifera-treated groups revealed absence of collagenous fibrous connective tissues. Moreover, basil oil and $M$. oleifera significantly down regulate caspase- 3 expression where reduced caspase-positive apoptotic cells were noticed indicating that both may act as anti-fibrotic and anti-apoptotic agents.

Collectively, the present investigation offers strong evidence for the hepato-protective, antifibrotic, anti-inflammatory and antioxidative efficiencies of both basil oil and $M$. oleifera leaves aqueous extract with the primary role for $M$. oleifera.

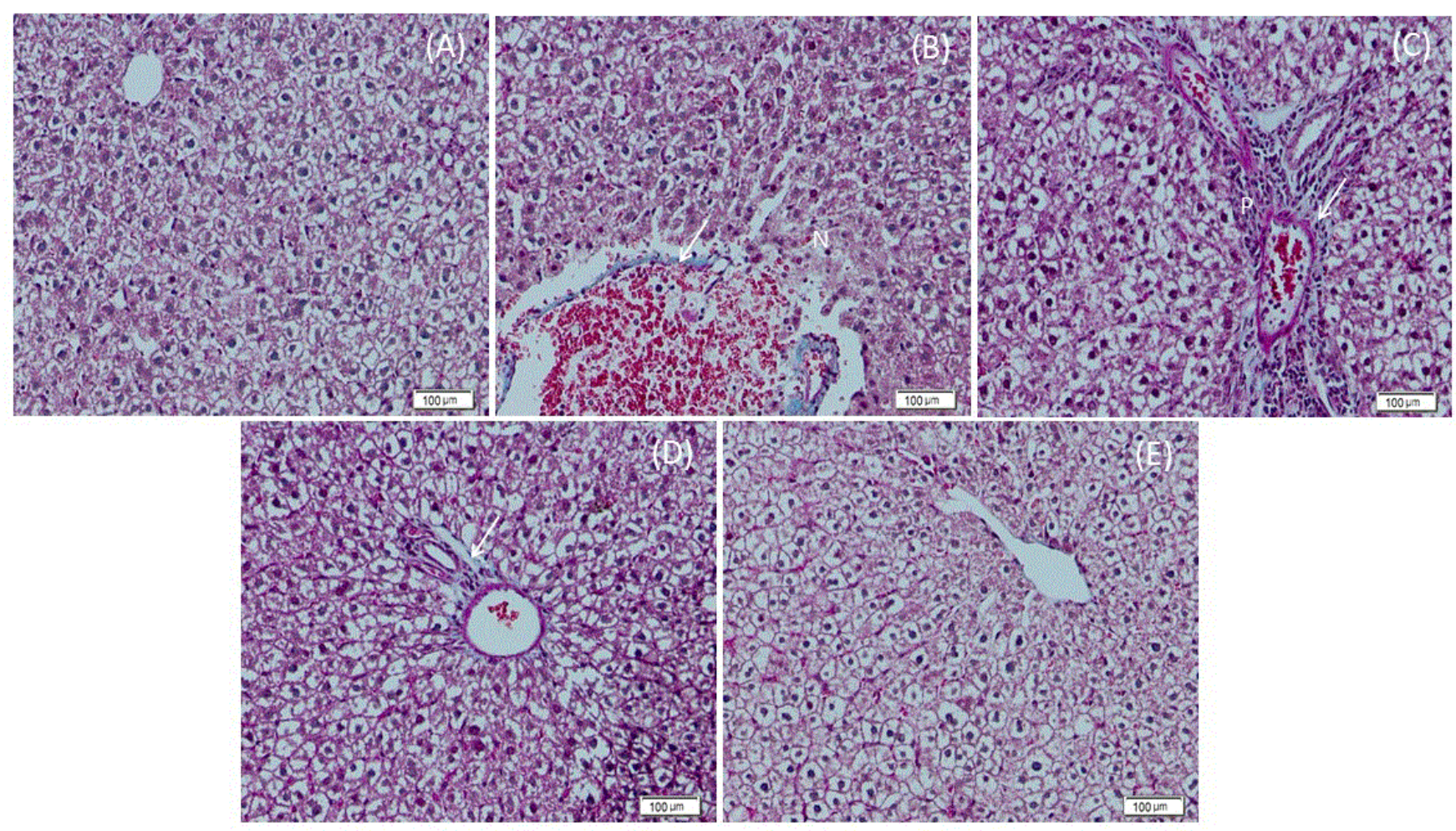

Figure 5: Photomicrographs of liver sections of different treatment groups stained by Masson's trichrome. (A) Control group, (B and C) Lornoxicam-treated group. (D) LOR+Basil oil-treated group. (E) LOR+M. oleifera treated group. Notice: mild early fibrosis (arrow), focal hepatic necrosis $(\mathrm{N})$.

\section{Conclusion}

Conclusion intake should be highlighted considering Lornoxicam widespread use as an anti-inflammatory and analgesic. Regarding the obtained findings; we proposed the hepato-protective activities of the basil oil and $M$. oleifera leaves extract on LOR-induced hepatotoxicity may be due to presence of phytochemicals that may act as antioxidants. Both herbal ingredients could represent a new tools offering herbal therapy which will be helpful for treatment of drug-induced hepatotoxicity.

\section{Conflict of Interest}

None of the authors has any financial interest or any possible conflict of interest related to the manuscript. 


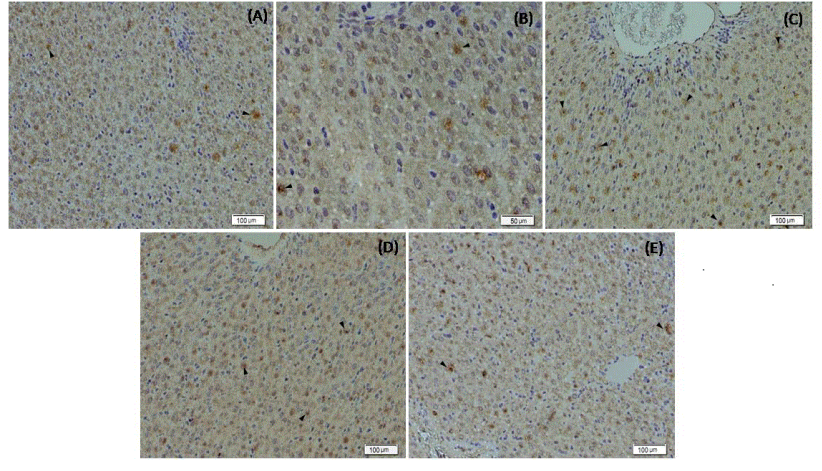

Figure 6: Photomicrographs of immunohistochemical staining (anti-Caspase-3 antibody) in liver sections. Figure 6A and 6B: Control group. Figure 6C: Lornoxicam -treated group. Figure 6D: LOR+ Basil oil-treated group. Figure $6 \mathrm{E}: \mathrm{LOR}+M$. oleifera -treated group. Detectable caspase-3 activity (arrowheads) were observed in all group's livers, higher positively intracytoplasmic brown expression of Caspase- 3 were noticed in Lornoxicam-treated group. IHC staining counterstained with haematoxylin.

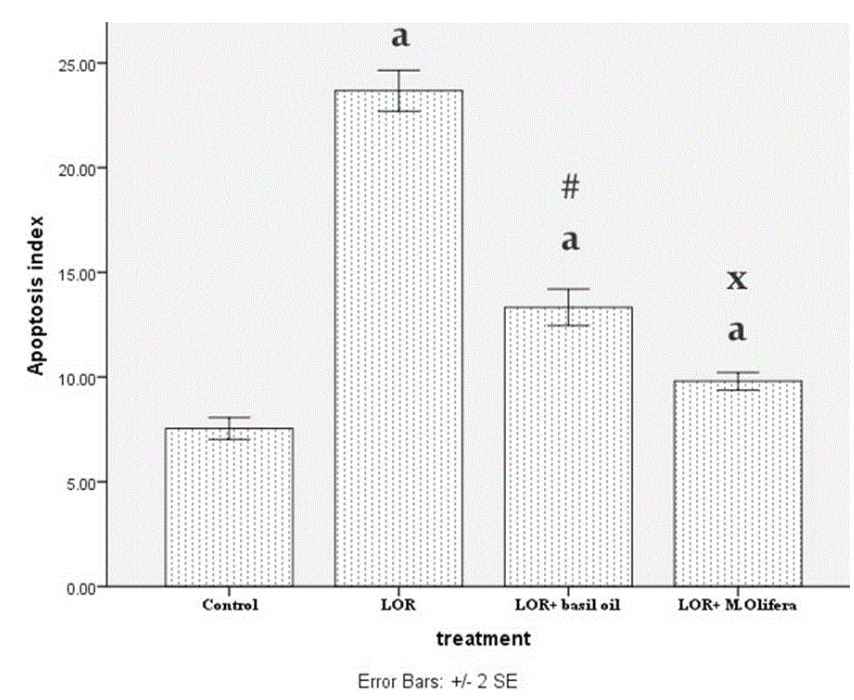

Figure 6F: Apoptosis index. Values are expressed as mean \pm S.E.M. and analyzed using one-way ANOVA followed by the Duncan analysis at $\mathrm{P}<0.05$. aP compared to control, \# $\mathrm{P}$ compared to lornoxicam and $\mathrm{LOR}+M$. oleifera - treated groups, $\mathrm{xP}$ compared to lornoxicam and LOR+basil oil- treated groups.

\section{References}

1. Radhofer-Welte S, Rabasseda X (2000) Lornoxicam, a new potent NSAID with an improved tolerability profile. Drugs Today (Barc) 36: 55-76.

2. Malhi H, Gores GJ, Lemasters JJ (2006) Apoptosis and necrosis in the liver: a tale of two deaths Hepatology 43: S31-44.

3. Kerr JF, Wyllie AH, Currie AR (1972) Apoptosis: a basic biological phenomenon with wide-ranging implications in tissue kinetics. $\mathrm{Br} \mathrm{J}$ Cancer 26: 239-257.
4. Monteiro SM, Dos Santos NM, Calejo M, Fontainhas-Fernandes A, Sousa M (2009) Copper toxicity in gills of the teleost fish, Oreochromis niloticus: effects in apoptosis induction and cell proleiferation. Aquat Toxicol 94: 219-228.

5. Earnshaw WC, Martins LM, Kaufmann SH (1999) Mammalian caspases: structure, activation, substrates, and functions during apoptosis. Annu Rev Biochem 68: 383-424.

6. Liu D, Li C, Chen Y, Burnett C, Liu X Y, Downs S, et al. (2004) nuclear import of proinflammatory transcription factors is required for massive liver apoptosis induced by bacterial lipopolysaccharide. J Biol Chem 279: 48434-48442.

7. Gurtu V, Kain SR, Zhang G (1997) Fluorometric and colorimetric detection of caspase activity associated with apoptosis. Anal Biochem 251: 98-102.

8. Gao D, Xu Z, Qiao P, Liu S, Zhang L, et al. (2013) Cadmium induces liver cell apoptosis through caspase-3A activation in purse red common carp (Cyprinus carpio). PLoS One 8: e83423.

9. Bozin B, Mimica-Dukic N, Simin N, Anackov G (2006) Characterization of the volatile composition of essential oils of some lamiaceae spices and the antimicrobial and antioxidant activities of the entire oils. J Agric Food Chem 54: 1822-1828.

10. Manosroi J, Dhumtanom P, Manosroi A (2006) Anti-proleiferative activity of essential oil extracted from Thai medicinal plants on $\mathrm{KB}$ and P388 cell lines. Cancer Lett 235: 114-120.

11. de Almeida I, Alviano DS, Vieira DP, Alves PB, Blank AF, et al. (2007) Antigiardial activity of Ocimum basilicum essential oil. Parasitol Res 101: 443-452.

12. Duke JA (2008) Basil as the Holy Hindu Highness. Alternative and Complementary Therapies 14: 5-8.

13. Djakalia B, Guichard BL, Soumaila D (2011) Effect of Moringa oleifera on growth performance and health status of young post-weaning rabbits. Res J Poultry Sc 4: 7-13.

14. Goyal BR, Agrawal BB, Goyal RK, Mehta AA (2007) Phyto-pharmacology of Moringa oleifera Lam, An overview. Nat Prod Rad 6: 347-353.

15. Anwar F, Latif S, Ashraf M, Gilani AH (2007) Moringa oleifera : a food plant with multiple medicinal uses. Phytother Res 21: 17-25.

16. Fakurazi S, Hairuszah I, Nanthini U (2008) Moringa oleifera Lam prevents acetaminophen induced liver injury through restoration of glutathione level. Food Chem Toxicol 46: 2611-2615.

17. Hamza AA (2010) Ameliorative effects of Moringa oleifera Lam seed extract on liver fibrosis in rats. Food Chem Toxicol 48: 345-355.

18. Ndiaye M, Dieye AM, Mariko F, Tall A, Sall Diallo A, et al. (2002) Contribution to the study of the anti-inflammatory activity of Moringa oleifera (moringaceae). Dakar Med 47: 210-212.

19. Maisuthisakul P, Suttajit M, Pongsawatmanit R (2007) Assessment of phenolic content and free radical-scavenging capacity of some Thai indigenous plants. Food Chem 100: 1409-1418.

20. Oboh G, Puntel RL, Rocha JBT (2007) Hot Pepper (Cap- sicum annuum, Tepin and Capsicum chinese, Habanero) Prev ents Fe2+-Induced Lipid Peroxidation in Brain-in Vitro, Food Chemistry 102: 178- 185.

21. Lako J, Trenerry C, Wahlquist M, Wattanapenpaiboon N, Sotheeswaran, et al. (2007) Phytochemical flavonols, carotenoids and the antioxidant properties of a wide selection of Fizian fruits, vegetables and other readily available foods. Food Chem 101: 1727-1741.

22. Ayan E, Bayram Kaplan M, Koksel O, Tamer L, Karabacak T, et al. (2008) Efficiency of lornoxicam in lung and trachea injury caused by peroxynitrite. Pulm Pharmacol Ther 21: 201-207.

23. Reitman S and Frankle S (1957) Glutamic oxaloacetic transaminse colorimetric method. Am J Clin Pathol 28: 53-56.

24. Belfield A, Goldberg DM (1971) Revised assay for serum phenyl phosphatase activity using 4-amino-antipyrine. Enzyme 12: 561-573.

25. Evelson P, Travacio M, Repetto M, Escobar J, Llesuy S, et al. (2001) Evaluation of total reactive antioxidant potential (TRAP) of tissue homogenates and their cytosols. Arch Biochem Biophys 388: 261-266. 
26. Beutler E, Duron O, Kelly BM (1963) Improved method for the determination of blood glutathione. J Lab Clin Med 61: 882-888.

27. Aebi H (1984) Catalase in vitro. Methods Enzymol 105: 121-126.

28. Paglia DE, Valentine WN (1967) Studies on the quantitative and qualitative characterization of erythrocyte glutathione peroxidase. J Lab Clin Med 70: 158-169.

29. Goldberg DM, Spooner RJ (1983) Assay of glutathione reductase. In: Bergmeyen HV, editor Methods of enzymatic analysis. Florida: Verlag Chemie Deerfield Beach 3: 258-265.

30. Kornberg A and Horecker BL (1955) Methods in Enzymology. Academic Press, New York 1: 323.

31. Montgomery HA and Dymock JF (1961) The determination of nitrite in water Analyst. 86: 414-416.

32. Satoh K (1978) Serum lipid peroxide in cerebrovascular disorders determined by a new colorimetric method. Clin Chim Acta 90: 37-43.

33. Ohkawa H, Ohishi N, Yagi K (1979) Assay for lipid peroxides in animal tissues by thiobarbituric acid reaction. Anal Biochem 95: 351- 358.

34. Perandones CE, Illera VA, Peckham D, Stunz LL, Ashman RF (1993) Regulation of apoptosis in vitro in mature murine spleen $\mathrm{T}$ cells. J Immunol 151: 3521-3529.

35. Denny PC, Denny PA, Allerton SE (1983) Determination of sialic acid using 2-thiobarbituric acid in the absence of hazardous sodium arsenite. Clin Chim Acta 131: 333-336.

36. Warren L (1959) The thiobarbituric acid assay of sialic acids. J Biol Chem 234: 1971-1975.

37. Keerthidaa G, Priya V, Jayamathi P (2011) Protective Role of Plumbagin on Glycoprotein Changes in Fibrosarcoma Induced Rats. Asian J Exp Biol Sci 2: 502-505.

38. Knedel M, Böttger R (1967) A kinetic method for determination of the activity of pseudocholinesterase (acylcholine acyl-hydrolase 3.1.1.8.). Klin Wochenschr 45: 325-327.

39. Sáez-Valero J, Tornel PL, Muñoz-Delgado E, Vidal CJ (1993) Amphiphilic and hydrophilic forms of acetyl- and butyrylcholinesterase in human brain. J Neurosci Res 35: 678-689.

40. Aviram M, Rosenblat M, Bisgaier CL, Newton RS, Primo-Parmo SL, et al. (1998) Paraoxonase inhibits high-density lipoprotein oxidation and preserves its functions. A possible peroxidative role for paraoxonase. J Clin Invest 101: 1581-1590.

41. Kettle AJ, Winterbourn CC (1994) Assays for the chlorination activity of myeloperoxidase. Methods Enzymol 233: 502-512.

42. Lowry OH, Rosebrough NJ, Farr AL, Randall RJ (1951) Protein measurement with the Folin phenol reagent. J Biol Chem 193: 265-275.

43. Bancroft JD, Gamble M (2008) Theory and Practice of Histological Techniques. (6th Edn) Philadelphia, PA Churchill Livingstone Elsevier.

44. Taylor CR and Rudbeck L (2013) Guidebook to Immunohistochemical Staining Methods (6th Edn) Dako Denmark A/S, An Agilent Technologies Company.

45. Shuna Y, Zheng J, Jiang Z, Shi C, Li J, et al. (2013) Protective Effect of NAcetylserotonin against Acute Hepatic Ischemia-Reperfusion Injury in Mice. Int J Mol Sci 14, 17680-17693.

46. Jones, Douglas H (1989) Statistical Methods, (8th Edn) Snedecor GW and Cochran WG (Eds) ERIC.

47. Bianchi M, Panerai AE (2002) Effects of lornoxicam, piroxicam, and meloxicam in a model of thermal hindpaw hyperalgesia induced by formalin injection in rat tail. Pharmacol Res 45: 101-105.
48. Bonnabry P, Leemann T, Dayer P (1996) Role of human liver microsomal CYP2C9 in the biotransformation of lornoxicam. Eur J Clin Pharmacol 49: 305-308.

49. Anne-Christine M and Patrick DM (2008) Biotransformations Leading to Toxic Metabolites: Chemical Aspect. Wermuth's The Practice of Medicinal Chemistry pp: 674-696.

50. Taoka Y, Okajima K, Uchiba M, Murakami K, Kushimoto S, et al. (1997) Role of neutrophils in spinal cord injury in the rat. Neuroscience 79: 1177-1182.

51. Cebeci E, Oner FA, Usta M, Yurdakul S, Erguney M (2011) Evaluation of oxidative stress, the activities of paraoxonase and arylesterase in patients with subclinic hypothyroidism. Acta Biomed 82: 214-222.

52. Yesilova Y, Turan E, Ucmak D, Selek S, Halil Yavuz Ä, et al. (2012) Reduced serum paraoxonase-1 levels in vitiligo: further evidence of oxidative stress. Redox Rep 17: 214-218.

53. Ofek K, Krabbe KS, Evron T, Debecco M, Nielsen AR, et al. (2007) Cholinergic status modulations in human volunteers under acute inflammation. J Mol Med (Berl) 85: 1239-1251.

54. Das UN (2007) Acetylcholinesterase and butyrylcholinesterase as possible markers of low-grade systemic inflammation. Med Sci Monit 13: RA214-221.

55. Jung M, Hotter G, Vinas J, Sola A (2009) Cisplatin up regulates mitochondrial nitric oxide synthase and peroxynitrite formation to promote renal injury. Toxicol Appl Pharmacol 234: 236-246.

56. Kandeel M, Abdelaziz I, Elhabashy N, Hegazy H, Tolba Y (2011) Nephrotoxicity and oxidative stress of single large dose or two divided doses of gentamicin in rats. Pak J Biol Sci 14: 627-633.

57. Choi BM, Pae HO, Jang SI, Kim YM, Chung HT (2002) Nitric oxide as a pro-apoptotic as well as anti-apoptotic modulator. J Biochem Mol Biol 35: $116-126$

58. McVicker BL, Tuma P L, Kharbanda KK, Lee SM, Tuma DJ (2009) Relationship between oxidative stress and hepatic glutathione levels in ethanol-mediated apoptosis of polarized hepatic cells. World J Gastroenterol 15: 2609-2616.

59. Kancheva VD (2009) Phenolic antioxidants-radical-scavenging and chain-breaking activity: A comparative study. Eur J Lipid Sci Technol 111: 1072-1089.

60. Wei A, Shibamoto $T$ (2010) Antioxidant/lipoxygenase inhibitory activities and chemical compositions of selected essential oils. J Agric Food Chem 58: 7218-7225.

61. Orhan I, Kartal M, Kan Y, Sener B (2008) Activity of essential oils and individual components against acetyl- and butyrylcholinesterase. $\mathrm{Z}$ Naturforsch C 63: 547-553.

62. Dasgupta N, De B (2007) Antioxidant activity of some leafy vegetables of India: a comparative study. Food Chem 101: 471- 474

63. Singh BN, Singh BR, Singh RL, Prakash D, Dhakarey R, et al. (2009) Oxidative DNA damage protective activity, antioxidant and anti-quorum sensing potentials of Moringa oleifera. Food Chem Toxicol 47: 1109-1116.

64. Verma AR, Vijayakumar M, Mathela CS, Rao CV (2009) In vitro and in vivo antioxidant properties of different fractions of Moringa oleifera leaves. Food Chem Toxicol 47: 2196-2201. 